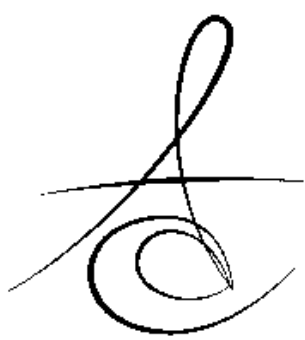

Makale Kodu/Article code: 1699

Makale Gönderilme tarihi: 15.05.2014

Kabul Tarihi: 15.07.2014

\section{MAKSİLLER OVERDENTURELARDA KULLANILAN İKİ FARKLI BAĞLANTI SİSTEMİNİN DEĞERLENDİRİLMESİ: İKİ OLGU SUNUMU*}

\section{EVALUATION OF TWO DIFFERENT ATTACHMENT SYSTEM USED FOR MAXILLARY OVERDENTURE: TWO CASE REPORTS*}

Dr. Cumhur KORKMAZ*

\section{ÖZET}

Tam dişsiz hastanın protetik tedavisi diş hekimleri için büyük bir sorun teşkil etmektedir. Tam protez, dişsiz maksilla ve mandibula protezi olarak sıklıkla kullanılmaktadır. Bununla birlikte bu durum, retansiyon ve stabilite eksikliği gibi sorunlar oluşturmaktadır. İmplantlar, dişsiz maksilla tedavisinde iyi bir alternatiftirler. Bu vaka raporunda; tam dişsiz anterior maksiller alana, dörder adet implant yerleştirilen tam dişsiz maksillaya sahip iki vaka sunulmaktadır. Bu iki vakada farklı iki bağlantı sistemi (lokator ve bar) kullanılarak implant destekli maksiller overdenture protez yapımı planlanmıştır. Final restorasyonlar estetik ve fonksiyonel açıdan memnun edici sonuçlar ortaya koymuştur.

Anahtar Kelimeler: Dental implant, dişsiz çene, overdenture.

\section{GİRIŞ}

Dişlerin varlığı, fonksiyon, fonasyon ve estetik açıdan büyük önem taşır. Çene kemiği; mevcut olan dişlerin çiğneme fonksiyonu sırasında oluşan kuvvetleri çene kemiğine iletimini sağladığı sürece yoğunluğunu, yapısını korur ve biyostimüle olur. Ancak dişlerin mevcut olmadığı kemikte bu stimülasyon olmadığından kemiğin trabeküler yapısında ve yoğunluğunda azalmalar meydana gelir. Bu durum üst çenede özellikle anterior bölgede posterior alana göre daha hızlı ve fazla oluşur. ${ }^{1}$

\section{ABSTRACT}

The prosthetic rehabilitation of edentulous patient has been a major challenge for dentists. The complete removable denture is commonly used for edentulous maxillary and mandibular denture. However, this situation has drawbacks such as lack of retention and stability. Implants are a good alternative for the treatment of edentulous maxilla. In this case report is described the two completely edentulous maxillary patients were inserted 4 dental implants in the edentulous anterior maxillary area. In this two cases are planned two different connection systems (locator and custom-made bar) used for implant-retained maxillary complete overdentures. The final restorations provided satisfactory aesthetic and functional results.

Key Words: Dental implantation, edentulous jaw, overdenture

Dişsiz üst çenenin rehabilitasyonu bu açıdan önem taşır. Özellikle üst çene anterior bölgedeki diş kayıpları sonucu hızlanan kemik kaybı, alt-üst çene ilişkisinin de bozulmasına sebep olur. Bu hastalar protetik tedavide önemli bir grubu oluşturur ve rehabilitasyonlarında spesifik protetik prensiplerin uygulanması gereklidir., ${ }^{2,3}$ Dişsiz maksillanın rehabilitasyonunda mandibuladan farklı olarak dikkat edilmesi gereken kriterleri şu şekilde sıralayabiliriz:

1. Rezorpsiyonun derecesi ve kalan kemik miktarı,

2. İmplantların tahmini yeri ve aksları,

3. Yumuşak doku miktarı,

* Balıkesir Asker Hastanesi, Balıkesir/Türkiye.

** GATA Haydarpaşa Eğitim Hastanesi Diş Servisi, İstanbul/Türkiye.

${ }^{\#}$ Bu çalışma 3-5 EKIM 2013 tarihinde ICOI World Congress XXX Istanbul/TURKEY'de poster olarak sunulmuştur. 
4. Fasyal morfoloji,

5. Estetik,

6. Fonksiyon ve fonasyon ${ }^{2}$.

$\mathrm{Bu}$ spesifik prensiplerin yanında genel olarak dişsiz çenelerin implant destekli protezle rehabilitasyonunda dikkat edilmesi gereken unsurlar ise:

1. Ark üzerinde implant dağılımı, lokalizasyonları ve sayısı,

2. Karşıt arktaki dentisyon (doğal diş ya da protez tipi),

3. Alt-üst çene ilişkisi,

4. Tüm bu faktörlerden etkilenen okluzal düzen,

5. Estetik yapılacak özveri, şeklinde özetlenebilir. ${ }^{2}$

Dişsiz arkın implant destekli rehabilitasyonunda

bu kriterlerin planlanması protetik başarının sağlanmasında zorunludur.

Hasta memnuniyeti ve çene kemiğinin biyostimülasyonu açısından sabit protetik planlamayı destekleyecek sayıda implant kullanımı optimum başarıyı sağlamada önemli iken, özellikle tam dişsiz üst çenede çoğu zaman yeterli kemik miktarının bulunamaması ve ekonomik sebepler gibi nedenlerden dolayı daha az sayıda implant kullanımı zorunlu olmaktadır. ${ }^{3-5}$

Marjinal kemik kaybı, implant tedavisinin başarısında en önemli faktörlerden biridir. Marjinal kemik kaybı miktarının birinci yıl klinik kullanım sonunda yaklaşık $1 \mathrm{~mm}$, bu periyoddan sonraki yıllık kemik kaybı için kabul edilebilir sınır $0.2 \mathrm{~mm}$ olarak tanımlanmış olup ${ }^{1,3}, 86$ hastayla yapılan bir overdenture çalışmasında yıllık marjinal kemik kaybı 0,8 mm, sonraki yıllar için $0,1 \mathrm{~mm}$ olarak rapor edilmiştir. ${ }^{4}$

İmplant destekli overdenture planlamalarında implant ile protez arasında hassas bağlantı sistemlerinden yararlanılır. Bu hassas bağlantı sistemleri, bağlantı sisteminde sağladıkları esneme özelliklerine göre; dikey esneklik sağlayanlar (örneğin lokator), menteşe esnekliği sağlayanlar (örneğin barlı sistemler), rotasyon esnekliği sağlayanlar (örneğin çivi başlı tutucular), translasyon esnekliği sağlayanlar, kombinasyon esnekliği sağlayanlar (örneğin Dolder bar) ve universal esneklik sağlayanlar olarak sıralanabilir. ${ }^{6}$

$\mathrm{Bu}$ makalede; üst çene tam dişsiz iki vakanın dörder implant destek ve iki farklı tutucu sistem kullanılarak yapılan protetik tedavisinin sunulması amaçlanmıştır.

\section{OLGU SUNUMU}

Yaşları 48 ve 54 olmak üzere iki erkek hasta tam dişsiz üst çenelerine 4'er adet implant yapılmış halde GATA Haydarpaşa Eğitim Hastanesi Diş Servisi Protetik Diş Tedavisi Kısmına başvurdu. Hastalardan alınan anamnez neticesinde implantların farklı bir merkezde yapıldığı ve hastanın şehir değiştirmesi nedeniyle protez aşamasının implant yapılan yerde devam edilemediği öğrenildi.

48 yaşındaki 1 . vakada üst çenede simetrik olarak lateral ve birinci premolar bölgesine olmak üzere 4 adet implant yerleştirildiği ve karşıt arkta metal destekli seramik kuronlarla full ark restorasyonun mevcut olduğu belirlendi (Şekil 1). İmplant lokalizasyonu ve karşıt ark incelendiğinde hastaya lokator destekli overdenture yapımı planlandı.

54 yaşındaki 2. vakada ise dişsiz maksillada simetrik olarak kanin ve 1. premolar bölgesine dört adet implant yapıldığı, karşıt arkta ise doğal dentisyonun mevcut olduğu görüldü (Şekil 2). Bu hastaya bar bağlantılı overdenture yapımı planlandı.

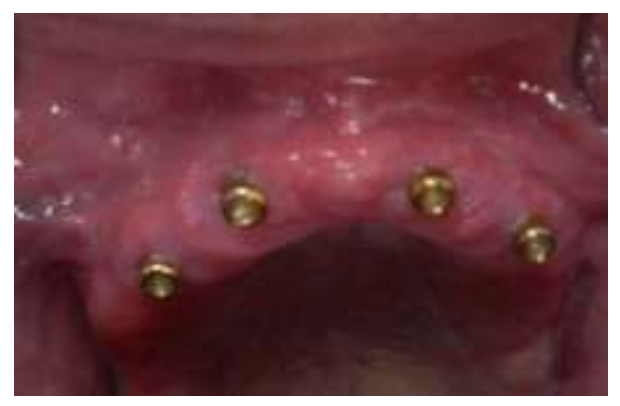

Şekil 1. 1. vaka implant ve lokatorların ağız içi görünümü.

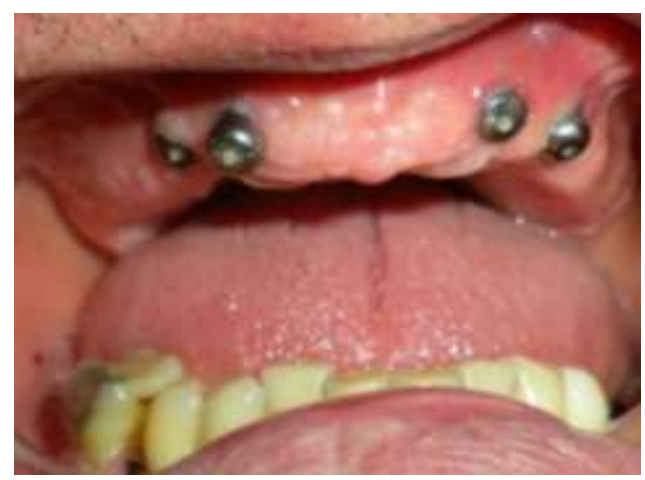

Şekil 2. 2. vaka implant iyileşme başlıklarının ağız içi görünümü 
Her iki hastanın panoramik radyografileri alınarak implant çevresi kemik dokunun kontrolü yapıldı, klinik ve radyografik kontrollerde implant destekler ile ilgili herhangi bir sorun olmadığı görüldü. Ardından hastalara protetik planlama anlatılarak yazıı onayları alındı ve protetik işlemler başlatıldı.

1.vakada lokatorlar implantlara yerleştirilerek firma önerileri doğrultusunda torklandı. 2. vakada ise implant transfer parçaları takıldı. Her iki hastadan silikon ölçü maddesi (Zetaplus, Zhermack, Rovigo, Italy) ile ölçüler alındı.

İkinci aşamada 2. vakanın bar döküm sisteminin provası yapılarak pasif uyumu kontrol edildi (Şekil 3). Her iki vakada dikey boyut ve sentrik ilişki kaydedildi, diş rengi ve boyutu tespit edildi. Üçüncü aşamada dişli prova yapılarak alt-üst çene ilişkisi ve estetik kontrolü yapıldı. Dördüncü aşamada 2. vakanın bar bağlantısı implantlara uygulanarak torklandı. Her iki protezin overdenture ve implant alt yapı uyumunun pasifliği, hasta tarafından kolay takılıp-çıkartılabilirliği kontrol edildi. Akrilik rezin kısımların anterior bölgede dudağı yeterli destekleyip-desteklemediği kontrol edildi. Açma-kapama ve lateral hareketlerin artikülasyon kağıdı ile kontrolü ardından gerekli selektif möllemeler yapılarak protezler hastalara teslim edildi (Şekil 4,5).

1. ve 6. haftalarda yapılan kontrollerde protezdoku ve protez-implant ara bağlantı uyumlarının iyi olduğu görüldü. 6.ayda alınan radyografilerde implant çevresi kemik yapının kontrolü yapıldı. Planlanan protetik tedavide hasta uyumunun yüksek olduğu görüldü.

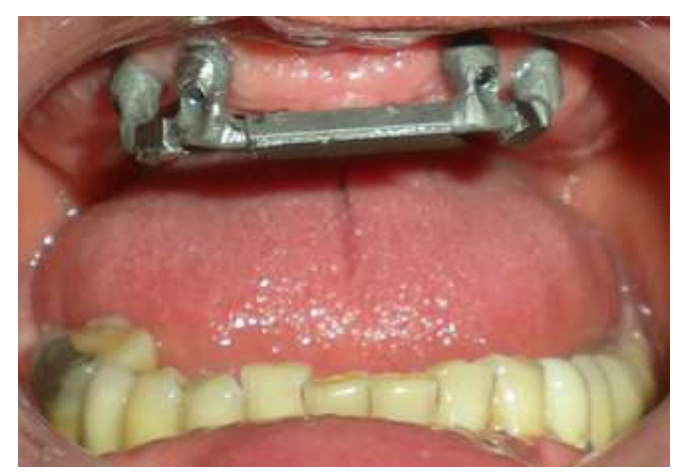

Şekil 3. 2. vaka bar dökümün ağız içi görünümü.

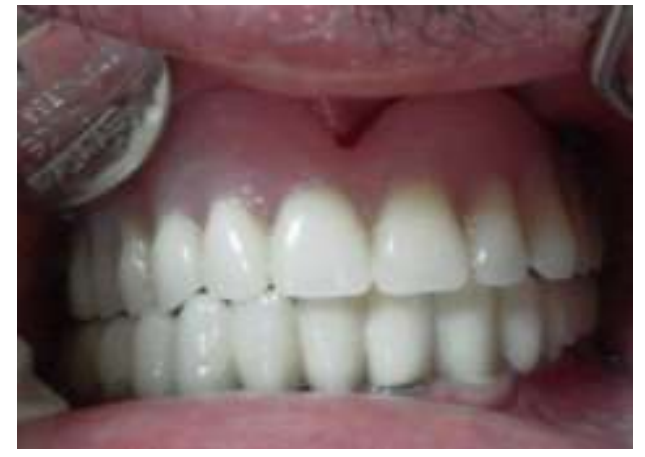

Şekil 4. 1. vaka protezinin hastaya uyumlanmış hali.

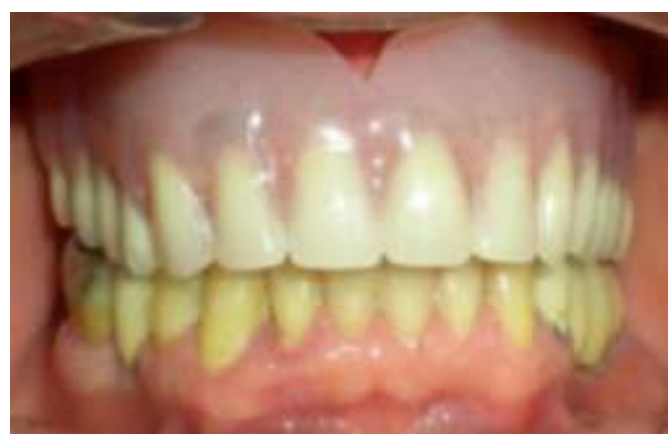

Şekil 5. 2. vaka protezinin hastaya uyumlanmış hali.

\section{TARTIŞMA}

Dişsiz üst çene rehabilitasyon vakaları, genellikle ileri derecede rezorpsiyon ve bu nedenle bozulmuş alt-üst çene ilişkisi nedeniyle klinisyenin zorlandığı vakalardır. İmplant cerrahisinde elde edilen gelişmeler, bu zor vakalarda tek tercih olan klasik tam protezlerinin yerine alternatif tedavi seçenekleri sunulmasını sağlamıştır. Yapılan hayat kalitesi çalışmalarında, implant destekli protezlerin estetik, psikolojik ve fonksiyonel açıdan klasik tam protezlere göre daha iyi sonuçlar verdiği belirlenmiştir. ${ }^{7-11}$

Çene kemiğinin rezorbsiyonunu engellemede implantların gösterdiği başarı bir tarafa, tam ve bölümlü protezlerin çiğneme kuvvetlerini çene kemiğinin sadece yüzeyine iletebildiklerinin ve dolayısı ile çene kemiğindeki rezorpsiyonun devam etmesine sebep olmaları nedeniyle, özellikle tam dişsiz maksillada anterior bölgeye yapılacak implant destekli overdenture uygulamalarının, uzun süreli tedavide üstün başarı sağlayacağı ve kemik rezorpsiyonunun 
önüne geçileceği nedeniyle doğru bir endikasyon olduğu değerlendirilmektedir. ${ }^{1}$

Tam dişsizlik vakalarında implant destekli overdenture protezlere destek olacak implant sayısı konusunda farklı görüşler mevcuttur. ${ }^{9,12}$ Literatürde kemik yapısının iki implant destek için uygun olduğu durumlarda ball ataçman destekli overdenture kullanılması tavsiye edilirken, dört implant desteğin kullanılabileceği durumlarda bar bağlantılı destek önerilmiştir. ${ }^{5,13}$ Üst çene tam dişsizlikte ise iki implanttan destek alan ball ataçman kullanımının yeterli retansiyon sağlayamadığı, bu nedenle 4 implant destekten yararlanılması gerektiği bildirilmiştir. ${ }^{13}$ İmplant desteklerin sayısı kadar lokasyonu da protetik tedavinn planlamasını etkiler. Her iki vakada dört implant destek kullanıması ile beraber 1 . vakada implant desteklerin lokalizasyonu nedeniyle lokator kullanımı, 2. vakada yine implant desteklerinin lokasyonunun uygun olması nedeniyle bar bağlantıı overdenture kullanımı uygun bulunmuştur. Lokator tutucu ile overdenture proteze dikey esneklik özelliği kazandırılabilirken, barlı tutucularla menteşe esnekliği kazandırılmış olur. ${ }^{6}$ Bu esneklik çiğneme kuvvetlerinin implant ve mukoza üzerine kuvvet kırıı aracılığı ile iletilmesi, kemik yıkımının engellenmesi amaçlanır.

Overdenture protez kullanımı; tam dişsiz çenelerde sabit planlama için yeterli sayıda implant yerleştirilmesinin mümkün olmadığı vakalarda iyi bir alternatiftir. ${ }^{14,15}$ Az sayıda implant kullanılabildiği gibi, tutuculuk ve dengenin daha iyi sağlanabildiği protezler yapılması mümkündür. Sunulan vakalarda iki farkı bağlantı sistemi kullanılmış ve her ikisinin de retansiyon ve stabilizasyon açısından yeterli olduğu gözlenmiştir. İmplant destekli overdenture protezlerde klasik tam protezlere kıyasla hasta memnuniyetinin yüksek olduğu çalışmalarla desteklenmiştir., 7,10,12

İmplant destekli restorasyonlarda uygulanan oklüzyon tipi ve oklüzal dizayn, yapılan protezin uzun dönem başarısında en önemli unsur olarak karşımıza çıkmaktadır. Overdenture'larda normal krete sahip bir hastada bilateral balanslı lingualize okluzyon önerilse de aşırı rezorbe krete sahip hastalarda monoplane okluzyon kullanılmalıdır. Overdenture protezlerin stabilitesi açısından bilateral balanslı okluzyonun avantajlı olduğu yönünde görüş birliği olmasına rağmen, bu fikri destekleyebilecek ölçüde klinik çalışma bulunmamaktadır. ${ }^{16,17}$
Özellikle rezorbe üst çene anterior bölgede overdenture protezin akrilik rezin kısımları kullanılarak kaybolan dudak desteğinin sağlanabilir olması estetik olarak da avantaj sağlamaktadır.

Yapılan çalışmalarda overdenture protezlerin implant destekli sabit protezlere göre hasta tarafından daha kolay temizlenebildiği bildirilmiştir. ${ }^{10,13}$ Hastalara protezin tesliminden sonra yapılan kontrollerde protez temizliğinin kolaylığı, hastanın proteze alışma sürecini de olumlu etkilediği değerlendirilmiştir.

Sonuç olarak; hastalarda implant destekli overdenture uygulamasının estetik, fonksiyon ve fonasyon özellikleri yüksek bir tedavi sağladığı, hasta uyumunun bu bağlamda yüksek olduğu gözlenmiştir.

\section{KAYNAKLAR}

1. Misch, CE. Dental İmplant Protezler. Nobel Tip Kitabevleri, 2009, S: 1-120.

2. Mercscke-Stern, RD., Taylor, TD., Belser, U. Management of the edentulous patient. Clin Oral Impl Res: 2000;11:108-125.

3. Chan MF, Narhi TO, de Baat C, Kalk W. Treatment of the atrophic edentulous maxilla with implant-supported overdentures: a review of the literature. Int J Prosthodont 1998;11:7-15.

4. Naert I, Quirynen M, Theuniers G, van Steenberghe D. Prosthetic aspects of osseointegrated fixtures supporting overdentures. A 4-year report. J Prosthet Dent 1991;65:671-680.

5. Wim S, Gerry M, Gerrit VD, Henry JA M. Attachment of clips in a bar-retained maxillary implant overdenture: a clinical report. J Prosthet Dent 2012;107:353-357.

6. Geçkili, O, Bural, C., Bilmenoğlu, Ç. İmplant Destekli Tam Protezlerde Kullanılan Tutucu Sistemler, EÜ Dişhek Fak Derg 2010; 31: 9-18.

7. Çakır, O., Kazancıoğlu, HO, Çelik, G. Değer, S. Evaluation of The Efficiency of Mandibular Conventional and Implant Prostheses in a Group of Turkish Patients: A Quality of Life Study, J Prosthodont 2014. 1-7 doi.10.1111/JOPR.12120.

8. Hutton JE, Heath MR, Chai JY, Harnett J, Jemt $T$, Johns RB, et al. Factors related to success and failure rates at 3-year follow-up in a multicenter study of overdentures supported by Branemark 
implants. Int J Oral Maxillofac Implants 1995; 10:33-42.

9. Kronstrom M, Widbom C, Soderfeldt B. Patient evaluation after treatment with maxillary implant-supported overdentures. Clin Implant Dent Relat Res 2006;8:39-43.

10. Adell, R., Eriksson, B., Lekholm, U., Branemark, PI., Jemt, T. A long-term follow-up of tissueintegrated implants inthe treatment of the totally edentulous jaw. Inter J Oral Maxillofac Imp 1990;5: 347-59.

11. Albrektsson, T., Zarb,GA. Current interpretations of the osseointegrated response. Clinical significance. Int J Prosthodont, 1993;6: 95-105.

12. Ekfeldt $A$, Christiansson $U$, Eriksson $T$, Linden $U$, Lundqvist $S$, Rundcrantz $T$, et al. A retrospective analysis of factors associated with multiple implant failures in maxillae. Clin Oral Implants Res 2001;12:462-7.

13. Lewis S, Sharma A, Nishimura R. Treatment of edentulous maxillae with osseointegrated implants. J Prosthet Dent 1992;68:503-8.

14. Ogino, Y., Kihara, M., Yamada, J., Toriva, K., Koyano, K. Implant treatments for edentulous maxilla with anterior hyperfunction, J Oral Implantol, 2014; Jan 23 Epub ahead of print).

15. Wim S, Gerry M, Gerrit VD, Henry JA M. Attachment of clips in a barretained maxillary implant overdenture: a clinical report. J Prosthet Dent 2012;107:353-357.

16. Kim Y, Oh TJ, Misch CE, Wang HL. Occlusal considerations in implant therapy:clinical guidelines with biomechanical rationale. Clin Oral Implants Res. 2005 Feb;16(1):26-35.

17. Vanlığlu B, Özkan Y. İmplant destekli restorasyonlarda oklüzyon. Atatürk Üniv. Diş Hek. Fak. Derg. Supplement:4 2011: 57-64.

\section{Yazışma Adresi}

Cumhur KORKMAZ

Balıkesir Asker Hastanesi

Diş Servisi/Balıkesir

Gsm :0 5325496590

E-mail: cmhkorkmaz@hotmail.com
18. 